\title{
IsoCon Processing of Alloy 718Plus ${ }^{\mathrm{TM}}$
}

\author{
Joe Lemsky ${ }^{1}$, Kevin Kloske ${ }^{2}$, Tom Bayha ${ }^{3}$ \\ ${ }^{1}$ Ladish Co., Inc.; 5481 S. Packard Avenue; Cudahy, WI 53110 \\ ${ }^{2}$ Pratt \& Whitney; 400 Main Street; East Hartford, CT 06108 \\ ${ }^{3}$ Allvac; 2020 Ashcraft Avenue; Monroe, NC 28111
}

\begin{abstract}
Advanced thermo-mechanical processing techniques have allowed the forging industry to improve upon new and existing alloys and to provide enhanced microstructures and properties for components. Processes that develop and control uniform grain sizes in components have long been desired by the aerospace industry. Also, processes that retain metallurgical strain from deformation processes have also shown great value. Retained metallurgical strain can provide two benefits: 1) assistance in precipitation processes, such as with DA718, and 2) increase the amount of strain hardening in the alloy and resultant component, such as IsoCon Waspaloy.

718 Plus ${ }^{\mathrm{TM}}$ is an alloy that has a relatively narrow processing window to produce uniform fine grain sizes. This new alloy has also shown gains in mechanical properties from direct age and retained metallurgical strain processing. An effort to apply IsoCon Alloy 718 Plus $^{\mathrm{TM}}$ has been undertaken. In this process a controlled isothermal forging step provides a highly refined preform geometry with uniform grain structure ("Iso" step in IsoCon). The preform is subsequently conventionally hammer forged ("Con" step) to develop the optimum metallurgical strain for enhanced mechanical properties. This paper will review the results from characterization work performed on IsoCon 718Plus ${ }^{\mathrm{TM}}$ Alloy forgings.
\end{abstract}

